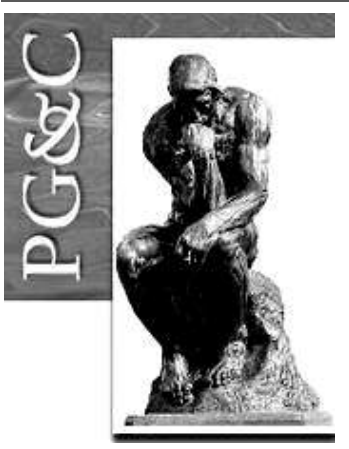

\title{
RESSIGNIFICAR O RETORNO DE EXPERIÊNCIA PARA ROMPER COM O SILÊNCIO ORGANIZACIONAL: O LUGAR DO DEBATE SOBRE O TRABALHO
}

\author{
Raoni Rocha \\ Doutor em Ergonomia pela Universidade de Bordeaux, França. \\ Professor da Universidade Federal de Itajubá, Brasil. \\ E-mail: raoni@unifei.edu.br
}

\begin{abstract}
Resumo
O presente artigo discute os sistemas de retorno de experiência presentes nas organizações contemporâneas, frequentemente baseados em lógicas punitivistas e culpabilizantes. Para isso, este artigo lança mão de uma pesquisa participativa realizada numa empresa francesa de distribuição de energia elétrica imersa na lógica do silêncio organizacional, na qual os trabalhadores deixam de declarar as situações de risco vividas no campo. Como consequência, os dispositivos de retorno de experiência perdem o seu sentido original, qual seja, um espaço de aprendizagem, passando a ser configurados como ferramentas de punição aos trabalhadores que erram ou infringem regras de segurança. No intuito de construir uma gestão da segurança que ultrapasse os sistemas altamente hierarquizados e afastados do campo operacional, a pesquisa mostra o desenvolvimento de um dispositivo de retorno da experiência baseado no debate sobre o trabalho em diferentes escalões da empresa. Os resultados mostram contribuições sistêmicas para a organização, desde que algumas condições para a implantação do debate sejam respeitadas, concluindo que as práticas reais de trabalho devem ganhar lugar central nos processos gestão das organizações para que a segurança das empresas possa avançar.
\end{abstract}

Palavras-chave: Gestão da segurança. Silêncio organizacional. Retorno da experiência. Debate sobre o trabalho. Subsidiariedade.

\section{RESIGNIFY THE OPERATIONAL EXPERIENCE FEEDBACK TO BREAK THE ORGANIZATIONAL SILENCE: THE PLACE OF DEBATE ON WORK}

\begin{abstract}
This article discusses the feedback systems present in contemporary organizations, often based on punitive and blaming logic. To this end, this article makes use of a participative research carried out in a French power distribution company immersed in the logic of organizational silence, in which workers stop declaring the situations of risk experienced in the field. As a consequence, the feedback devices lose their original meaning, which is a learning space, and are now configured as tools to punish workers who make mistakes or break safety rules. In order to build a security management that goes beyond highly hierarchical systems and away from the operational field, research shows the development of a feedback device based on the debate about the work at different levels of the company. The results show systemic contributions to the organization, provided that some conditions for the implementation of the debate are respected, concluding that the real work practices must gain a central place in the management processes of the organizations so that the security of the companies can advance.
\end{abstract}

Keywords: Safety management. Organizational silence. Operational experience feedback. Debate on work. Subsidiarity.

Perspectivas em Gestão \& Conhecimento, João Pessoa, v. 10, n. 3, p. 280-294, set./dez. 2020. DOI: https://dx.doi.org/10.22478/ufpb.2236-417X.2020v10n3.55713

http://periodicos.ufpb.br/ojs2/index.php/pgc. ISSN: 2236-417X. Publicação sob Licença (cc) EY-NC-ND 


\section{INTRODUÇÃO}

A evolução dos sistemas sociotécnicos demanda um desenvolvimento sempre crescente dos meios implantados para garantir a segurança. Novas regras, ferramentas e tecnologias são criadas para acompanhar essa evolução, levando os trabalhadores a conhecer diferentes tipos de mudanças no trabalho. Por um lado, os gerentes operacionais se encontram cada vez mais obrigados a produzir resultados gerenciais, por vezes distantes da realidade operacional (ANTONELLO; RUAS, 2005; DETCHESSAHAR, 2014). Por outro, os procedimentos de segurança se multiplicam com o objetivo de contemplar todas as situações previsíveis, podendo gerar circunstâncias nas quais o respeito irrestrito a todas as regras de segurança pode se tornar difícil (ALMEIDA; GONÇALVES, 2020). Por si só, a infração de uma regra não se torna um problema, já que é frequentemente invisível aos olhos dos gestores. Ela somente se configura como disfunção quando vem acompanhada de um incidente ou acidente. Nestes casos, o erro humano e a infração de algumas regras são colocados em destaque pelos gestores e o profissionalismo dos operadores é colocado em questão (AMALBERTI et al., 2018). Em razão disso, as formas de retorno da experiência se tornam frágeis nas empresas, de forma que essas situações permanecem frequentemente escondidas no campo operacional (MBAYE et al., 2014).

Para avançarmos no campo da gestão da segurança, é necessário dar luz à experiência operacional e à discussão do trabalho real no interior das organizações, de forma que o retorno da experiência seja capaz de alimentar os sistemas de gestão das organizações. Sob este prisma, uma pesquisa participativa e qualitativa - aquela na qual "a palavra escrita ocupa lugar de destaque" e "os dados coletados aparecem sob a forma de transcrições de entrevistas, anotações de campo (...)" (GODOY, 1995, p. 62) - foi desenvolvida em uma empresa francesa de distribuição de energia elétrica com um rígido sistema de controle e aplicação de sanções nos casos de desrespeito às regras de segurança. Essa pesquisa buscou ressignificar os sistemas de retorno de experiência, de forma a romper o silêncio organizacional por meio do desenvolvimento de espaços de debate sobre o trabalho entre colaboradores de diferentes escalões da empresa estudada. Desde que algumas condições sejam respeitadas, esses espaços podem trazer numerosas contribuições para a organização e para os trabalhadores envolvidos.

O objetivo deste artigo é, assim, apresentar esta pesquisa e mostrar as contribuições sistêmicas e condições para o desenvolvimento de uma abordagem que busque fazer do debate sobre o trabalho uma forma eficiente de retorno da experiência, que possibilite o desenvolvimento de uma organização capaz de antecipar situações geradoras de riscos a partir do compartilhamento e da discussão coletiva do trabalho cotidiano.

\section{REFERENCIAL BIBLIOGRÁFICO}

\subsection{0 silêncio organizacional e as suas consequências}

A organização das empresas contemporâneas é marcada por algumas características peculiares. Por um lado, se observa um grupo de gestores afastados do campo operacional, sobrecarregados com a produção de regras e indicadores (DETCHESSAHAR; JOURNÉ, 2018), exercendo uma gestão diretiva e hierarquizada (ICSI, 2017), criando novos procedimentos a cada novo evento não desejado do campo e controlando os trabalhadores de final de cadeia produtiva a cumprir fielmente esses procedimentos (AMALBERTI et al., 2018). Como consequência, é perceptível a redução da autonomia e do poder de agir dos indivíduos em campo (CLOT, 2010), uma frágil declaração de situações reais à gestão (BRINGAUD et al., 2016) e uma ruptura dos coletivos de trabalho da gestão com a operação (JOURNÉ et al., 2020).

Perspectivas em Gestão \& Conhecimento, João Pessoa, v. 10, n. 3, p. 280-294, set./dez. 2020. 
Dessa forma, as organizações se caracterizam por trabalhadores operacionais mudos, que não querem falar do campo, e gestores surdos, que não querem ouvir o campo (ROCHA et al., 2019). Temos, assim, todas as condições para produzir o chamado "silêncio organizacional", quando "a escolha dominante dos empregados no interior de diversas organizações é guardar para si próprios as suas opiniões e preocupações em relação aos problemas organizacionais" (MORRISON; MILLIKEN, 2000, p. 707). A Figura 1 representa essa discussão.

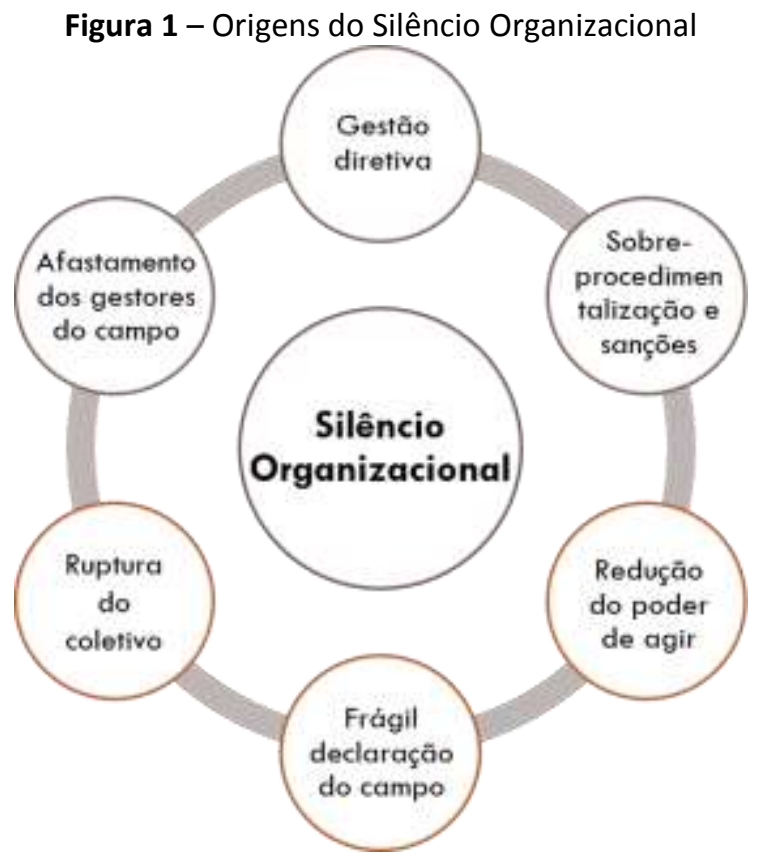

Fonte: elaborado pelo autor

Pinder e Harlos (2001) definem o conceito como uma escolha intencional em não comunicar as informações críticas sobre a organização a outros membros capazes de tratar esses aspectos. Essas definições mostram que o silêncio do empregado é fruto de uma decisão consciente e deliberada, e que as informações omitidas podem se tornar críticas para o sistema (VAN DYNE; ANG; BOTERO, 2003).

Ora, a motivação que determina os trabalhadores a interromper ou não o silêncio é diretamente ligada às condições oferecidas pelos gestores. Como Morrison e Milliken (2000) afirmam, o silêncio ocorre devido à ausência de humildade gerencial herdada de percursos escolares prestigiosos, negando a possibilidade de uma inteligência mais próxima do campo. Nas empresas onde o silêncio impera, os gestores julgam os empregados como pouco confiáveis, considerando os retornos negativos dos trabalhadores como não legítimos e acreditando que a crítica é uma ameaça às suas próprias competências. Assim, para os gestores, o acordo é um sinal de boa saúde da organização enquanto o desacordo deve ser evitado. Esse raciocínio vai ao sentido da "ideologia do bom profissional" (CARBALLEDA; GARRIGOU, 2001) ou o fato de que "o bom profissional não deve ter problemas, pois ele deve saber tratá-los... Uma pessoa que fizesse parte abertamente dos seus problemas correria o risco de ser julgada pelos seus pares e sua hierarquia como um mal profissional, ou mesmo como o responsável das disfunções encontradas no interior da organização" (p. 101). Como consequência, observamos uma forte centralização do poder decisional, que exclui a participação dos empregados e favorece a ausência de mecanismos formais para captar as situações reais do campo.

Perspectivas em Gestão \& Conhecimento, João Pessoa, v. 10, n. 3, p. 280-294, set./dez. 2020. 
Duas razões desencorajam qualquer forma de expressão dos operadores (ROCHA; MOLLO; DANIELLOU, 2015): o medo de repercussões negativas em decorrência da situação levantada e a percepção de uma frágil comunicação gerencial a respeito da resolução do problema sinalizado. $O$ indivíduo, temendo a forma com que os gestores ou seus pares receberão a mensagem, e estando convencidos de que os seus chefes estão pouco dispostos a escutá-los ou a tratar alguns problemas do campo, não divulgam as informações, já que, de toda forma, ele pensa que isso não acarretará nenhum resultado prático.

\subsection{Reconstrução do Retorno da Experiência através do debate sobre o trabalho}

Na busca em se ultrapassar a limitada abordagem da gestão da segurança baseada somente em regras ou indicadores numéricos, muitas organizações confiam a gestão da segurança nos sistemas de Retorno da Experiência, ou a análise de incidentes do campo para gerar aprendizado e prevenção sobre acidentes futuros (AVEN; KROHN, 2014). Essas ações que buscam analisar o trabalho para definir ações de melhoria, buscando aprender por meio da prática, podendo oferecer elementos reais para a segurança (BRINGAUD et al., 2016). As tentativas de desenvolvimento de sistemas de REX nas empresas normalmente se materializam em dispositivos como briefings de segurança, Diálogos Diários de Segurança (DDS), sistemas de sinalização de incidentes (como as caixinhas de sugestões) ou difusão de "boas práticas" após a ocorrência de um acidente.

Embora construída para trazer a experiência do campo aos processos de gestão, as práticas de REX nas empresas, muito frequentemente, perdem o sentido. Em razão da pressão de tempo a que os trabalhadores estão submetidos, os briefings de segurança comumente ocorridos entre supervisor e operador antes de uma intervenção são muitas vezes simplificados à uma passagem rápida da ordem de serviço sem qualquer diálogo sobre a intervenção entre eles. Os "diálogos diários de segurança" se deformam em monólogos semanais de assuntos diversos, já que se materializam pela presença de um supervisor ou técnico de segurança que palestra sobre assuntos muitas vezes sem qualquer relação com segurança. Os sistemas de sinalização de incidentes são, com muita frequência, ilustrados por caixinhas de sugestões que se tornam obsoletas, uma vez que o trabalhador não se sente confortável para escrever a sugestão e depositá-la na caixinha, ou porque, quando feitas, a gestão não realiza um tratamento adequado das sugestões. A difusão de boas práticas pósacidente se resume, comumente, à exposição em painéis na empresa e ao envio por email de um documento com um resumo da análise realizada e de recomendações aos operadores, que em grande parte das vezes são ignoradas pelos mesmos (ROCHA et al., 2019).

Paralelamente a esse cenário, o REX contemporâneo costuma ter um viés altamente retrospectivo - baseado exclusivamente em eventos passados - e punitivista - utilizado como forma de aplicar sanções formais ou informais nos indivíduos em razão de determinadas situações flagradas no campo. É a chamada cultura da culpa e do medo promovida por diferentes empresas (WESTBROOK et al., 2015). Esse contexto leva os trabalhadores a deixarem de se expressar nos mecanismos de REX ou, quando o fazem, o produto daquilo que é verbalizado está quase sempre associado a terceiros, mas dificilmente concerne os próprios erros e violações às regras, cotidianamente cometidos por qualquer trabalhador (MBAYE et al., 2014). A percepção de ausência de mudança das situações sinalizadas pode reduzir ainda mais a disposição para a comunicação de eventos (SUJAN, 2015). Assim, a presença da sanção e a ausência de tratamento de situações declaradas podem ser uma maneira de impedir a declaração de situações reais pelos trabalhadores e, dessa forma, enfraquecer o sistema de retorno de experiência.

Para avançar na gestão da segurança, é necessário retomar o sentido original dos sistemas de retorno de experiência, qual seja, um diálogo protegido sobre o trabalho

Perspectivas em Gestão \& Conhecimento, João Pessoa, v. 10, n. 3, p. 280-294, set./dez. 2020. 
executado de forma a trazer aprendizado para os indivíduos e para a organização. Construir um espaço protegido significa que nenhuma situação trazida para o debate seja passível de sanção por parte da gestão. Simultaneamente, nesses espaços devem ser fomentados debates não somente sobre eventos não desejados, mas também sobre aqueles nos quais tudo ocorreu aparentemente dentro da normalidade, permitindo os operadores atingir os seus objetivos no cotidiano, apesar das condições variáveis e do aparecimento de perturbações (ROCHA et al., 2015).

Os sistemas de REX, portanto, ganham sentido se utilizados como espaços de debate sobre o trabalho real. É uma forma de romper com o silêncio organizacional e aportar elementos reais para a reflexão dos gestores sobre o campo operacional de trabalho.

\subsection{Princípio da subsidiariedade como condição do debate sobre o trabalho}

Não é possível desenvolver um debate sobre o trabalho sem se considerar a distribuição do poder de agir dos participantes (ROCHA et al., 2019). Essa reflexão nos leva ao princípio da subsidiariedade (MILLON-DELSOL, 1993), que trabalha com as noções de "poder" e "autonomia" de grupos sociais.

A ideia deste princípio é antiga, remontando a Aristóteles, quando descrevia uma cidade como um grupo hierarquicamente ordenado em partes menores, autossuficientes, que eventualmente fazem apelo à cidade para terem apoio em determinadas questões (LUYCKX, 1992). Barroche (2012) afirma que podemos também encontrar essa noção nos textos de São Tomás de Aquino, formalizada pela primeira vez pelo Papa Leão XIII, através da Teoria Social da Igreja Católica, depois das consequências da revolução industrial sobre a sociedade civil. Segundo ele, esta teoria sustenta que é um erro moral quando um nível social mais elevado executa ações que podem ser realizadas por um nível social hierarquicamente inferior, pois nós os privaríamos (o nível inferior) de suas próprias capacidades de tratamento de problemas. As responsabilidades devem, então, repousar, sobre os níveis sociais mais inferiores que puderem cumpri-las. Assim, a primeira célula social é a família, que deve decidir e tratar o que Ihe é pertinente. Em seguida, passamos aos outros níveis político-sociais: quarteirão, cidade, estado, país e planeta. Luyckx (1992) ilustra essa teoria afirmando que a sociedade deve intervir para reprimir jovens delinquentes quando a célula familiar não foi capaz de fazê-lo. Em função da gravidade do caso, ele pode ser tratado em instâncias superiores até o nível nacional. No outro sentido, é necessário decidir o que repousa sobre a responsabilidade dos níveis inferiores (estados, cidades, família) para que eles tenham autonomia para agir nos casos pertinentes. Destarte, o princípio da subsidiariedade deve funcionar nos dois sentidos: é necessário respeitar o nível de responsabilidade mais baixo possível sem intervenção de um nível superior, mas é igualmente necessária a intervenção de um nível superior a cada vez que o nível inferior falhar no tratamento da questão.

No mundo das empresas, o conceito de subsidiariedade se traduz pelo fato que um escalão gerencial superior não deve exercer as funções que podem ser eficientemente realizadas por um escalão hierarquicamente inferior. Ao mesmo tempo, os níveis inferiores devem estar apoiados na coordenação entre as suas atividades e aquelas da organização sistêmica (MELÉ, 2005).

Pradines (2004) desenvolve três condições ao conceito de subsidiariedade nas organizações: o princípio da competência, no qual o escalão superior é proibido de realizar qualquer tarefa que possa ser feita pelo escalão inferior, devendo as decisões serem tomadas no nível mais baixo possível; o princípio do socorro, em que o escalão superior tem o dever de cumprir as tarefas que o escalão inferior não puder tratar, de forma que sempre que um nível hierárquico não tiver os recursos suficientes para gerir uma situação, o nível superior deve se

Perspectivas em Gestão \& Conhecimento, João Pessoa, v. 10, n. 3, p. 280-294, set./dez. 2020. 
encarregar de fazê-lo; e o princípio da substituição, mostrando que o escalão inferior, quando tiver os recursos para tratar uma questão, é proibido de se esquivar dela.

O princípio da subsidiariedade nos remete, assim, à pesquisa permanente do nível mais pertinente para a ação a partir da articulação e do ajustamento dos diferentes coletivos da organização. Ele permite o desenvolvimento do coletivo de trabalho pela reflexão em torno da noção de poder de agir de cada nível hierárquico, ou seja, por meio do desenvolvimento da autonomia dos trabalhadores somado aos recursos oferecidos pela gestão a cada nível hierárquico.

\section{MATERIAIS E MÉTODOS}

Com o objetivo de instaurar espaços de debate para gerir questões de segurança, uma pesquisa empírica de natureza qualitativa foi realizada, durante 4 anos, numa empresa francesa de distribuição de energia elétrica. $O$ objetivo principal da pesquisa foi desenvolver espaços de debate sobre o trabalho (EDT) interligados pelo princípio da subsidiariedade como forma de romper o silêncio organizacional, trazer à luz os problemas de segurança aos gestores da empresa, para desenvolver formas de tratá-los. Dessa maneira, a ideia era trabalhar diretamente nas ferramentas de gestão da organização. Para isso, dois comitês foram formados: o Comitê Científico, composto pelos três pesquisadores responsáveis pelo projeto; e o Comitê de Pilotagem, composto pelos três pesquisadores e outros quatro representantes da direção da empresa. Ambos os comitês mantinham um diálogo constante com o Comitê de Direção (Codir) da empresa, formado pelos membros de sua diretoria.

O método de coleta de dados se compõe de duas grandes fases, cada uma com duração de 1,5 ano: uma fase de experimentação dos EDT, tendo por objetivo o desenvolvimento do debate das situações de campo ligadas à segurança; e uma fase de perenização/generalização dos EDT e de organização da subsidiariedade, conectando os espaços de debate locais com os escalões superiores da empresa.

Cada uma dessas duas fases comporta diversas etapas. A fase de experimentação das EDT compreende três subfases: a análise do trabalho; o tratamento das Situações de Ação Características - SAC - ou "classes de situações que os operadores muito provavelmente terão que gerir no futuro" (DANIELLOU, 2004, p. 366); e a experimentação de um dispositivo de debate. Na primeira subfase, denominada "Análise de trabalho", foi realizada uma Análise Ergonômica do Trabalho (GUÉRIN et al., 2001), método que consiste na observação das atividades reais de trabalho e em entrevistas com os trabalhadores. Essa fase colocou em evidência a ruptura do coletivo de trabalho e a ausência do feedback do campo, gerando o silêncio organizacional. Essas constatações nos conduziram a desenvolver uma fase experimental, em quatro unidades da empresa, de forma a implantar, em cada uma delas, um espaço de debate das situações de campo. Essa 2a subfase, denominada "Tratamento das SAC", teve o objetivo não somente de tratar as situações discutidas como também coconstruir um dispositivo cotidiano de tratamento coletivo de situações de campo. Foram realizadas, assim, quatro reuniões, com frequência de 2 em 2 semanas, nas quais o material coletado na fase anterior (situações concretas de risco) era colocado em discussão de forma a se buscar soluções coletivas com o grupo. Essa fase foi gravada e posteriormente o conteúdo foi transcrito. Em seguida, numa $3^{\text {a }}$ subfase, denominada "Experimentação do dispositivo de debate", um dispositivo de tratamento coletivo de situações de risco foi coconstruído em uma unidade piloto específica (ROCHA, 2014). Assim, sem a presença direta do pesquisador, os eletricistas traziam situações de risco do campo, discutiam entre si e buscavam soluções coletivas. Quatro dessas reuniões foram gravadas e o conteúdo foi posteriormente transcrito (o objetivo deste artigo se refere, principalmente, à 2a e 3 a subfase desta pesquisa). Uma vez desenvolvido esse dispositivo local de debate, o objetivo da pesquisa foi perenizá-lo e

Perspectivas em Gestão \& Conhecimento, João Pessoa, v. 10, n. 3, p. 280-294, set./dez. 2020. 
generalizá-lo para outras unidades. Para isso, foram realizadas formações com gestores de outras unidades sobre o dispositivo, com acompanhamento físico mensal junto a essas unidades durante 6 meses. Reuniões periódicas entre os comitês, assim como apresentações da pesquisa ao Codir ocorreram frequentemente durante o desenvolvimento do projeto.

Todas as reuniões das subfases de tratamento das SAC (2 a subfase) e de experimentação do dispositivo de debate ( 3 a subfase) foram gravadas e transcritas. $O$ material transcrito foi analisado de maneira qualitativa - baseado num tratamento temático de acordo com as grandes variáveis do debate - e quantitativa - com o auxílio do Actogram Kronos (KERGUELEN, 2003), software de tratamento de dados de observação cronológica de variáveis preestabelecidas. Uma vez toda a sessão codificada, os códigos com os tempos correspondentes eram trabalhados no Actogram Kronos. Os gráficos fornecidos por esse software permitiram obter uma "fotografia" da sessão completa, mostrando a evolução de todas as variáveis codificadas no mesmo gráfico (ROCHA; MOLLO; DANIELLOU, 2015). O Actogram Kronos também nos permitiu observar a variação dos dados entre as sessões registradas. Fazendo o mesmo processo em cada uma das 8 sessões analisadas, foi possível observar a variação de cada um desses códigos entre as diferentes sessões, e entre o início e o final do trabalho.

\section{O DESENVOLVIMENTO DE UM DEBATE “SUBSIDIÁRIO”}

Em cada uma das quatro unidades onde foi desenvolvido o debate sobre o trabalho, os dispositivos tomaram formas próprias, em razão das características do grupo e da organização local. De acordo com a vontade dos participantes, o debate poderia ser feito por meio de fotos, vídeos ou relatos de casos; as situações poderiam ser declaradas ao supervisor direto ou a algum outro gestor; os grupos poderiam ser compostos por eletricistas com a chefia direta, indireta ou mesmo com trabalhadores de outros setores.

$\mathrm{Na}$ unidade piloto, objeto deste artigo, foi implantado um dispositivo local de debate, no qual os eletricistas tiram fotos de eventos significativos do campo, relacionados tanto às situações que eles consideram anormais, quanto às adaptações às regras de segurança; repassam as fotos tomadas ao supervisor no debriefing (momento de conversa entre o eletricista e o supervisor sobre as intervenções realizadas ao longo do dia); e, após a seleção do supervisor, as fotos passam por um debate e tratamento coletivo.

\section{Exemplo: tratamento local da situação debatida}

O eletricista deveria intervir no contador elétrico de uma residência. Ao chegar, ele verifica que o contador se encontra destacado da parede e sobre uma cadeira, com fios energizados em exposição e, portanto, sob o risco de choque elétrico. No local, o eletricista realiza a segurança parcial do equipamento, isolando-o com fitas isolantes. Neste caso, também deveriam ser fixados adesivos alertando terceiros sobre o perigo, mas o eletricista não tem os adesivos no carro. Quando a situação é declarada na unidade, o grupo debate sobre o risco e a urgência do caso. Juntos, decidem disponibilizar fitas isolantes e adesivos

$\mathrm{Na}$ medida em que o dispositivo de debate funcionava, percebeu-se que os trabalhadores possuíam condições de tratar localmente uma série das situações discutidas, como mostra o exemplo acima, e ainda outros como fusíveis queimados, disjuntores danificados, ausência de parafusos ou fiação em alguns equipamentos, etc. Para tratá-los, o supervisor fazia, no início de cada sessão, um retorno ao grupo sobre as ações decididas na reunião anterior, aquelas que haviam sido implantadas e as que se encontravam pendentes.

Perspectivas em Gestão \& Conhecimento, João Pessoa, v. 10, n. 3, p. 280-294, set./dez. 2020. 
Segundo os eletricistas, esse ponto é fundamental para o prosseguimento e a perenização desse tipo de abordagem, uma vez que eles têm necessidade de saber o que se passa nas decisões tomadas em conjunto.

Apesar das contribuições produzidas, a implantação do dispositivo local de debate trouxe, também, algumas dificuldades na unidade, principalmente quando o grupo não tinha condições de tratar todas as situações discutidas. Segundo o supervisor (e coordenador do EDT), as principais dificuldades do dispositivo envolviam a "dificuldade de encontrar o interlocutor correto para resolver um problema que não podemos tratar localmente" e "quando encontrado, obter um retorno desse interlocutor sobre o assunto tratado". O grupo exprime, assim, a necessidade de declarar tais situações a outro nível gerencial que possa tratá-las. Essa necessidade constituiu, na verdade, uma condição fundamental para que o projeto fosse perenizado no interior do grupo. O que, então, fazer com essas situações não tratadas? A quem encaminhá-las? Como oferecer ao grupo os recursos necessários para analisar e gerir essas situações?

Essas questões expressas pelas necessidades dos participantes remetem às premissas do conceito de subsidiariedade discutidas anteriormente: o nível hierárquico superior é proibido de tratar qualquer situação que o nível hierárquico inferior puder tratar; o nível hierárquico superior tem o dever de tratar as situações que o nível hierárquico inferior não puder tratar; as situações devem ser tratadas no nível hierárquico inferior mais baixo possível da organização.

Partindo dessa ótica, foi decidido, em comum acordo com o setor de prevenção da empresa, envolvida no projeto desde o seu início, que as situações não tratadas na unidade piloto seriam, então, reportadas para o setor de prevenção em reuniões mensais pelo Comitê Prevenção-Segurança (CPS). Durante essas reuniões, seria igualmente garantido o feedback ao grupo local sobre o tratamento dessas situações. Assim, foi construído um 20 ciclo do dispositivo local de debate.

\section{Exemplo: tratamento no 20 nível hierárquico}

$\mathrm{Na}$ instalação de uma rede elétrica predial, o eletricista conecta o aparelho de verificação de tensão em dois polos energizados. Percebe então um curto-circuito. Como portava os Equipamentos de Proteção Individual, ele não sofreu nenhuma consequência, mas o aparelho se danificou. A questão principal neste caso envolveu o modelo do aparelho de verificação de tensão utilizado. A intervenção foi realizada num contador elétrico com duas saídas de eletricidade. Como de costume, o eletricista conecta o aparelho de verificação de tensão sobre os dois polos. Contudo, este é um novo modelo de contador elétrico, que possui três saídas de energia ao invés de duas. Se, num contador tradicional, são exatamente esses os polos a serem conectados, num contador com três saídas, se trata da chegada da energia ao contador. Os procedimentos, até então, não faziam distinção entre esses dois tipos de contadores e os eletricistas não eram treinados para isso. Por isso ocorreu o curto-circuito que danificou o aparelho. O eletricista, então, leva a foto para o debate na sua unidade e, como consequência, foi realizado um trabalho entre o responsável da unidade e o responsável pela prevenção para adaptar o procedimento e incorporar a nova situação nos treinamentos da empresa. O responsável da unidade comenta o processo: "Partindo desse caso, fizemos o procedimento evoluir, para que ele se aproximasse mais do trabalho real. Então, é um caso onde tínhamos um procedimento inadaptado porque as pessoas faziam completamente diferente no campo. E por esse sistema de declaração e debate coletivo, conseguimos modificá-lo". (Responsável da unidade).

Perspectivas em Gestão \& Conhecimento, João Pessoa, v. 10, n. 3, p. 280-294, set./dez. 2020. 
Se o setor da prevenção contribuiu com o tratamento de diversas situações discutidas, várias outras não puderam ser tratadas neste nível, pois faltavam os devidos recursos para isso. Seria necessário, assim, dar um suporte ao setor da prevenção nestes casos. Após uma negociação com os Diretores da empresa, foi definido que parte das reuniões trimestrais do Codir, às quais o responsável da prevenção participa, seriam utilizadas para tratar situações que não puderam ser tratadas nem localmente, nem no setor da prevenção. A Figura 2 apresenta a evolução do dispositivo sistêmico construído junto aos diferentes trabalhadores e escalões da empresa, seguida por um dos exemplos tratados no nível da Direção.

Figura 2 - Dispositivo de debate sobre o trabalho envolvendo dois níveis hierárquicos superiores

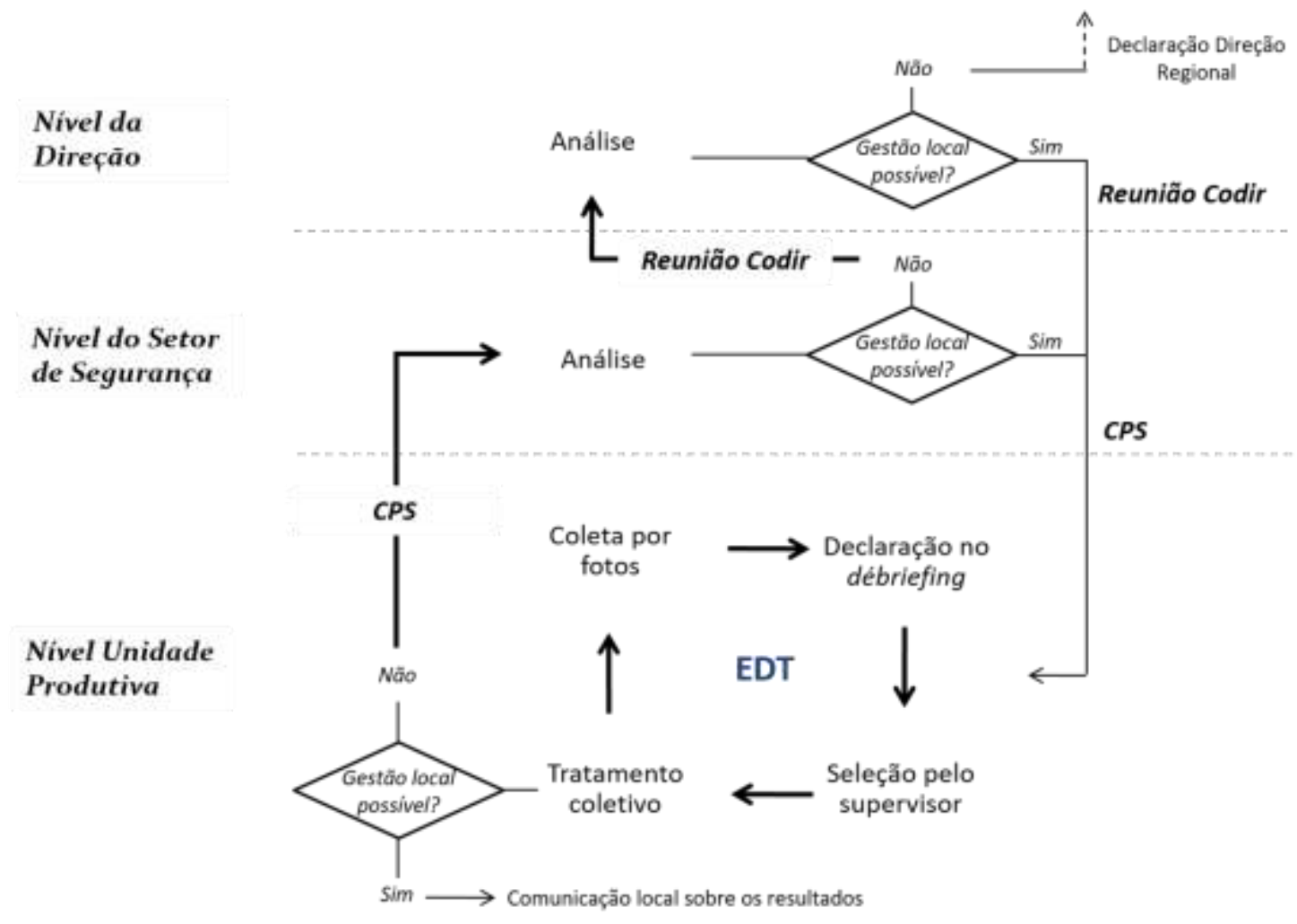

Fonte: elaborado pelo autor

Exemplo: situação tratada na Direção

Distribuidores elétricos urbanos posicionados em barrancos são situações que comportam um risco importante de quedas dos eletricistas que intervém nesses locais. A empresa já tem uma história de incidentes e acidentes neste tipo de situação. Segundo o supervisor, "é o tipo de situação inaceitável mas que sempre aconteceu". O supervisor remontou a situação junto ao responsável pela prevenção, que, sem os recursos necessários para gerila, a remontou ao Codir. Este último realizou, então, um trabalho junto aos prestadores de serviço responsáveis pela instalação de distribuidores elétricos urbanos, que tratam essa situação em algumas semanas. Um mês depois, o Codir dá o retorno ao setor da prevenção, e este ao grupo local, enviando a foto da situação completamente tratada. Ao mesmo tempo, foi realizado um trabalho junto aos prestadores para evitar a instalação de distribuidores novos em barrancos.

Os exemplos discutidos acima testemunham o funcionamento do dispositivo em nível sistêmico, da unidade piloto até a Direção da empresa. Todavia, se a Direção tem autonomia

Perspectivas em Gestão \& Conhecimento, João Pessoa, v. 10, n. 3, p. 280-294, set./dez. 2020. 
para tratar diversas situações que são declaradas pelas unidades, até mesmo ela não possui todos os meios para tratar qualquer tipo de situação que aparece. Outras instâncias, mais superiores, devem, a partir disso, integrar este ciclo de tratamento. 0 exemplo abaixo mostra um cenário em que a Direção alinhou o interlocutor hierarquicamente superior para tratar a situação discutida no grupo local.

\section{Exemplo: situação tratada em nível nacional}

Ao realizar uma intervenção num poste, uma chave inglesa cai da bolsa de ferramentas do eletricista. Ele então reporta a situação ao seu supervisor com o intuito de evitar acidentes com transeuntes. Durante o debate, os eletricistas levantaram diversas informações sobre este caso: a bolsa de ferramentas atual não é profunda o suficiente e é muito flexível, criando um risco importante de queda de ferramentas; em relação à antiga, a bolsa atual perdeu consideravelmente a sua rigidez. Essa situação foi reportada ao setor de prevenção e ao Codir. Os representantes do Codir, por não terem condições de tratar o caso, contataram o setor de materiais da empresa, no âmbito nacional. Como consequência, o responsável pelos materiais buscou desenvolver uma bolsa mais adaptada à atividade do grupo local. Um EDT foi, então, organizado por esse responsável junto aos eletricistas da unidade piloto. Os elementos do debate possibilitaram o desenvolvimento de um protótipo mais seguro, leve, rígido e com abas magnéticas, como mostrado abaixo.

\section{CONDIÇÕES DO DEBATE ESTRUTURADO SOBRE O TRABALHO PARA UM RETORNO DE EXPERIÊNCIA EFICIENTE}

O debate sobre o trabalho pôde criar condições de reconexão da gestão da empresa com a realidade do trabalho, tanto ao supervisor da unidade piloto, como aos gestores de outros níveis hierárquicos. $\mathrm{O}$ supervisor coordena, sugere e confronta os pontos de vistas. Ele dá atenção ao que diz cada um dos participantes e os interpela, se necessário, com questões do tipo "você pode nos contar um pouco mais sobre essa situação?" ou "como você reagiria em relação a isso?". Assim, ele acessa a realidade do trabalho dos eletricistas, as adaptações realizadas e as modalidades de tratamento das situações discutidas. Quando uma situação não possui os meios para ser tratada localmente ou quando o supervisor considera pertinente difundi-la a outras unidades da empresa, a situação pode ser reportada até o nível da Direção da empresa. Uma parte das reuniões gerenciais é, então, destinada para discutir sobre tais situações. Assim sendo, diferentes níveis gerenciais discutem sobre casos concretos reportados do campo, reaproximando-os do trabalho e dos problemas reais vividos por suas equipes. Essa abordagem possibilitou, assim, suprir uma lacuna dos sistemas atuais de gestão, enraizados em números e pouco conectados com a realidade do campo (AVEN; KROHN, 2014).

Em função destes resultados, é possível estabelecer quatro condições fundamentais para que o debate estruturado sobre o trabalho seja capaz de promover um retorno da experiência operacional de maneira eficiente.

A primeira condição é que os gestores sejam atores sociais que garantam e animem o debate. $\mathrm{Na}$ pesquisa apresentada nesse artigo, o supervisor teve um papel central na efetividade dos espaços de debate, sendo, ao mesmo tempo, mantenedor e animador do debate, ao alocar sistematicamente 20 minutos das reuniões semanais da unidade para a discussão coletiva em torno das fotos remontadas pelos eletricistas. Ao mesmo tempo, ele fomentava o debate - solicitando fotos e buscando a palavra dos participantes durante as reuniões - e organizava o tratamento das situações discutidas, realizando a comunicação

Perspectivas em Gestão \& Conhecimento, João Pessoa, v. 10, n. 3, p. 280-294, set./dez. 2020. 
daquelas não tratadas localmente ao setor da prevenção. Esse raciocínio se estende, também, aos gestores superiores, que asseguraram tanto a articulação entre o conteúdo das situações trabalhadas com os interlocutores de escalões superiores e inferiores, quanto o período de debate em parte de suas reuniões. No entanto, esse compromisso do gestor só será real se a organização oferecer condições para isso. O gestor que anima a reflexão em seu nível hierárquico pode fazer emergir alguns problemas para os quais ele não dispõe de recursos suficientes para geri-los. Neste caso, é necessário que algum outro gestor, hierarquicamente acima dele, assuma o tratamento da situação ou ofereça os recursos necessários para ele trate. Destarte, como defende Detchessahar (2014), o gestor só pode estimular a reflexão sobre o trabalho em seu nível hierárquico na condição que ele disponha também de outro espaço, no seu nível superior, que permita tratar a própria reflexão local.

A segunda condição é a necessidade de que o método seja coconstruído. Os espaços de debate tomaram formas variadas na pesquisa aqui discutida, se submetendo a adaptações particulares a fim de responder às especificidades da organização das unidades trabalhadas. $\mathrm{Na}$ unidade piloto, por exemplo, o debate foi feito por meio de fotos, enquanto que em outras ele foi realizado via vídeos ou relatos de casos. Da mesma forma, na unidade piloto os casos eram reportados ao supervisor, mas em outras unidades os reportes foram feitos a gestores operacionais. No que se refere à composição dos grupos, eles reuniram eletricistas com a chefia direta na unidade piloto, enquanto que em outras unidades a reunião se deu com a chefia indireta e, em outras ainda, com trabalhadores de outros setores. Essa coconstrução e adaptação da abordagem de acordo com as decisões dos trabalhadores foi primordial para a construção do dispositivo, na medida em que ela permite integrar um novo método numa estrutura organizacional já existente, sem que haja o acréscimo de reuniões extras e, por consequência, sem um custo suplementar aos trabalhadores envolvidos no projeto. Essa condição para se debater sobre o trabalho não é inédita, uma vez que Daniellou, Simard e Boissières (2010) já alertavam que o debate sobre o trabalho somente se torna durável e efetivo sob essa circunstância.

A terceira condição é que seja um debate baseado na confrontação com o real, com um coletivo regular e com possibilidade de ação. Qualquer processo de debate na pesquisa discutida nesse artigo esteve sempre centrado no real do trabalho, intermediado por fotos de situações do campo. Esta é uma das condições fundamentais do debate. Para isso, ele deve ser sustentado por materiais de suporte, como fotos, vídeos ou relatos, para que não haja digressões em relação ao assunto central (por exemplo, sobre questões salariais). Ao mesmo tempo em que se discute sobre o trabalho real, este deve ser feito dentro de uma lógica de confrontação de ideias. Se, muitas vezes, a dinâmica da concordância impera nas organizações atuais, de modo a fazer com que um gestor pense que o bom funcionário não é o que traz problemas, mas sim o que traz soluções, foi na confrontação dos discursos e saberes dos trabalhadores que observamos as situações mais ricas em termos de aprendizagem. Como já afirmavam Mollo e Nascimento (2013), a segurança não deve ser do domínio de pessoas isoladas na organização, mas objeto de confrontações entre diferentes lógicas provenientes dos diferentes escalões hierárquicos da empresa. Além disso, o debate sobre o trabalho nessa pesquisa só obteve resultados porque houve a presença regular dos membros da unidade piloto no EDT. Os espaços de debate devem contar, então, com uma base de integrantes constante, uma vez que é esse próprio coletivo que garante a perenidade desses espaços. Por fim, é necessário que os participantes do debate tenham a possibilidade de agir sobre as situações discutidas. Caso contrário, como verbaliza um dos eletricistas, "o debate sobre o trabalho certamente não terá vida longa se ficar só na retórica e não puder ser tratado".

A quarta condição é a disponibilização de recursos, aos níveis hierárquicos inferiores, para o tratamento das situações discutidas. É necessário que os participantes do debate tenham a possibilidade de agir sobre o produto da discussão. Se a situação de campo

Perspectivas em Gestão \& Conhecimento, João Pessoa, v. 10, n. 3, p. 280-294, set./dez. 2020. 
reportada é a "porta de entrada" da discussão entre os escalões hierárquicos, as questões de fundo dessa relação foram construídas baseadas no princípio da subsidiariedade: qual o nível pertinente mais inferior possível para tratar a situação discutida? Junto com essa questão, aparece outra: como o nível superior pode dar autonomia e poder de agir ao nível inferior, a fim de que este último tenha os recursos suficientes para tratar as situações remontadas? Dessa maneira, a cada situação que chegava ao setor de prevenção ou ao Codir, a reflexão construída não esteve somente no tratamento da situação, mas sobretudo sobre como oferecer recursos para que nível inferior pudesse tratar tal situação. Em outras palavras, se trata de desenvolver a subsidiariedade na prática, apoiar os níveis hierárquicos inferiores (Melé, 2005) e desenvolvendo os princípios da competência, do socorro e da substituição de Pradines (2004). Quando o responsável pela prevenção se ocupa da modificação de regra para o contador elétrico de 3 saídas para adaptá-la à realidade do campo ou quando a Direção realiza um trabalho junto aos prestadores de serviço de forma a evitar a instalação de novos contadores em barrancos, não é apenas a gestão dessas situações que está em jogo. Em ambos os casos, os trabalhadores locais ganharam autonomia e poder de agir para desenvolver as suas ações frente a situações semelhantes no futuro. Num contador elétrico de 3 saídas é agora possível conhecer a melhor forma de agir, assim como evitar acidentes em distribuidor urbanos novos. Dessa maneira, o objetivo do debate estruturado sobre o trabalho não é aumentar o número de situações reportadas aos outros níveis (e correr o risco de saturar as suas capacidades de tratamento), mas sim de reportar o mínimo possível, de forma que esse mínimo se torne o essencial e possa ter uma solução definitiva.

\section{CONSIDERAÇÕES FINAIS}

Essa pesquisa nos mostra uma forma de desenvolvimento de aprendizagem na ação, onde o conhecimento é produzido quando os trabalhadores rompem com o silêncio organizacional e debatem sobre o trabalho em espaços construídos e dedicados para isso. Ao fazer isso, os indivíduos da própria organização são capazes de resgatar a essência dos dispositivos de retorno de experiência, qual seja, realizar um debate sobre o trabalho real, que gere aprendizagem aos indivíduos e à organização, e assim, que construa a prevenção em segurança.

Se dispositivos de REX como briefings de segurança, DDS, sinalização de incidentes e difusão de boas práticas perderam o sentido nas empresas ao longo do tempo, se tornando ferramentas punitivistas e inertes em termos de geração de aprendizagem, é através da reconstrução do REX como um espaço de debate que os sistemas de retorno de experiência podem ganhar novo significado, reconectando a gestão com a realidade operacional, eliminando-se a lógica culpabilizante e gerando um ambiente efetivo de aprendizagem e prevenção.

A ressignificação de dispositivos de Retorno de Experiência, no entanto, não ocorre à esmo. Para que o REX se torne um espaço legítimo de debate algumas condições são necessárias, como a necessidade de que os gestores garantam e animem o debate; a necessidade de que o método seja coconstruído, com participação importante dos trabalhadores de final de linha produtiva; a necessidade de um debate que promova a confrontação com a realidade, com um coletivo regular e com possibilidade de agir sobre o que é discutido; e a necessidade de disponibilização de recursos, aos níveis hierárquicos inferiores, para o tratamento das situações discutidas. Caso essas condições não sejam garantidas e respeitadas, haverá aqui um risco importante de arrefecimento das possíveis contribuições oferecidas pelo REX como espaço de debate e de retorno às formas degradadas desse sistema encontradas nas empresas contemporâneas.

Perspectivas em Gestão \& Conhecimento, João Pessoa, v. 10, n. 3, p. 280-294, set./dez. 2020. 
Por fim, o método desenvolvido nesta pesquisa oferece um contraponto às formas clássicas de gestão da segurança adotadas nas empresas, ancoradas em métodos diretivos, hierarquizados, afastados do campo e imersos na lógica exclusiva de produção de regras e indicadores como forma de enquadrar e retratar a realidade operacional. A transformação de linhas de comunicação verticais em participação horizontal promovida pela pesquisa, através dos espaços de debate, explicita um sistema de gestão no qual os trabalhadores ocupam lugar central na gestão dos eventos de campo, possibilitando o acesso a problemáticas reais do campo operacional e ao seu tratamento de maneira durável. Trata-se, portanto, de uma perspectiva de gestão baseada na possibilidade de os indivíduos do final da cadeia produtiva contribuírem, dando luz à atividade real vivida no campo, para alimentar regras e indicadores produzidos pela empresa, de forma a tornar mais coerente a estrutura organizacional.

\section{REFERÊNCIAS}

ALMEIDA, I. M.; GONÇALVES, R. C. Quando as violações são ações adaptativas para resolver situações críticas no trabalho. Ação Ergonômica, v. 14, p. 132-136, 2020.

AMALBERTI, R.; SIMÕES, R. R.; VILELA, R. A. G.; MUNIZ, I. A. Gestão de segurança em sistemas complexos e perigosos - teorias e práticas: uma entrevista com René Amalberti. Revista Brasileira de Saúde Ocupacional, v. 43, p. 1-9, 2018.

ANTONELLO, C. S.; RUAS, R. Formação Gerencial: Pós-graduação Lato Sensu e o Papel das Comunidades de Prática. Revista de Administração Contemporânea, v. 9, n. 2, p. 35-58, 2005.

AVEN, T.; KROHN, B. S. A new perspective on how to understand, assess and manage risk and the unforeseen. Reliability Engineering and System Safety, 121, p. 1-10, 2014.

BARROCHE, J. État, libéralisme et christianisme - critique de la subsidiarité européenne. Dalloz-Sirey: 2012. 500 p.

BRINGAUD, V.; JOURNÉ, B.; MBAYE, S.; SALIOU, G.; TILLEMENT, S. (Dir.) Le Retour d’Expérience dans les organisations à risques, Paris: Presses des MINES, collection Vademecum, 2016.

CARBALledA, G.; GARRIGOU, A. Derrière le " stress ", un travail sous contraintes. In: P. Bouffartigue (dir), Cadres: la grande rupture. Paris: La Découverte, 2001. p. 89-105.

CLOT, Y. Trabalho e Poder de Agir. Tradução de Guilherme João Freitas Teixeira e Marlene Machado Zica Vianna. Belo Horizonte: FabreFactum, 2010. 368p.

DANIELLOU, F. L'ergonomie dans la conduite de projets de conception de systèmes de travail, In Falzon P., Ergonomie, Paris: PUF, 2004, p. 359-373.

DANIELLOU, F.; SIMARD, M.; BOISSIÈRES, I. Fatores Humanos e Organizacionais da Segurança Industrial. (Traduzido do original Facteurs humains et organisationnels de la sécurité industrielle por Rocha, R., Duarte, F., e Lima, F.), Toulouse: ICSI, 2010.

DETCHESSAHAR, M. Penser le travail pour repenser le management: réflexions à partir de l'enseignement social Chrétien. Revue Interdisciplinaire Management, Hommes et Entreprise - RIMHE, v. 4, n. 13, p. 68-81, 2014.

Perspectivas em Gestão \& Conhecimento, João Pessoa, v. 10, n. 3, p. 280-294, set./dez. 2020. 
DETCHESSAHAR, M.; JOURNÉ, B. Managing Strategic Discussions in Organizations: A Habermasian Perspective. M@n@gement, v. 21, n. 2, p. 771-800, 2018.

GODOY, A. S. Introdução à pesquisa qualitativa e suas possibilidades. Revista de Administração de Empresas, v. 35, n. 2, p. 57-63, 1995.

GÜÉRIN, F.; KERGUELEN, A.; LAVILLE, A.; DANIELLOU, F.; DURAFFOURG, J. Compreender o trabalho para transformá-lo: a prática da ergonomia. São Paulo: Edgard Blucher, 2001.

ICSI (2017). Safety Culture: from Understanding to Action. Issue 2018-01 of the Cahiers de la Sécurité Industrielle collection, Institut pour une Culture de Sécurité Industrielle (ICSI), Toulouse, France, 2017. Acessível em: http://www.icsi-eu.org/. Último acesso: 09 out. 2020.

JOURNÉ, B., LAROCHE, H., BIEDER, C., GILBERT, C. (Eds.). Human and Organisational Factors Practices and Strategies for a Changing World. Cham: Springer. 138 p. 2020.

KERGUELEN, A. Actogram Kronos pour Windows. Toulouse: Octarès, 2003.

LUYCKX, M. Histoire philosophique du principe de subsidiarité. Commission européenne, Cellule de prospective, 1992.

MBAYE, S.; TILLEMENT, S.; SALIOU, G.; BRINGAUD, V.; JOURNE, B. Pratiques de retour d'expérience (REX) pour un apprentissage organisationnel. Les Techniques de I'Ingenieur, Editions T.I., 2014.

MELÉ, D. Exploring the Principle of Subsidiarity in Organisational Forms. Journal of Business Ethics, v. 60, n. 3, p. 293-305, 2005.

MILLON-DELSOL, C. Le Principe de subsidiarité, Paris: Puf, coll. « Que sais-je ? », 1993.

MOLLO, V.; NASCIMENTO, A. Pratiques réflexives et développement des individus, des collectifs et des organizações. In P. Falzon, Ergonomie constructive. Paris : PUF, 2013, p. 164175.

MORRISON, E.; MILLIKEN, F. Organizational Silence: a barrier to change and development in a pluralistic world. The Academy of Management Review, 25 (4), p. 706-725, 2000.

PINDER, C.; HARLOS P. Employee Silence: Quiescence and Acquiescence as Responses to Perceived Injustice, in: Ferris Gerald R., Research in Personnel and Human Resources Management, vol. 20, Greenwich: JAI Press, p. 331-369, 2001.

PRADINES, P. Management: la subsidiarité, organisation de l'entreprise et enseignement de l'Église, 2004.

ROCHA, R. Du silence organisationnel au débat structuré sur le travail: les effets sur la sécurité et sur l'organisation, 2014. Tese de Doutorado - Universidade de Bordeaux, Bordeaux.

Perspectivas em Gestão \& Conhecimento, João Pessoa, v. 10, n. 3, p. 280-294, set./dez. 2020. 
ROCHA, R.; MOLLO, V.; DANIELLOU, F. Contributions and conditions of structured debates on work on safety construction. Safety Science, 113:192-199, 2019.

ROCHA, R.; MOLLO, V.; DANIELLOU, F. Work debate spaces: a tool for developing a participatory safety management. Applied Ergonomics, v. 46, p. 107-114, 2015.

SUJAN, M. An organisation without a memory: A qualitative study of hospital staff perceptions on reporting and organisational learning for patient safety. Reliability Engineering and System Safety, v. 144, p. 45-52, 2015.

VAN DYNE, L.; ANG, S.; BOTERO, I. C. Conceptualizing Employee Silence and Employee Voice as Multidimensional Constructs. Journal of Management Studies, v. 40, n. 6, p. 1359-1392, 2003.

WESTBROOK, J. I.; LI, L.; LEHNBOM, E.C.; BAYSARI, M. T.; BRAITHWAITE, J.; BURKE, R.; CONN, C.; DAY, R. O. What are incident reportings telling us? A comparative study at two Australian hospitals of medication errors identified at audit, detected by staff and reported to na incident system. Int J Qual Health Care, v. 27, p. 1-9, 2015. 